\title{
Skin advanced glycation end product accumulation and muscle strength among adult men
}

\author{
Haruki Momma • Kaijun Niu • Yoritoshi Kobayashi • Lei Guan • Mika Sato • Hui Guo • \\ Masahiko Chujo • Atsushi Otomo • Cui Yufei · Hiroko Tadaura • Tatsunori Saito • \\ Takefumi Mori $\cdot$ Toshio Miyata $\cdot$ Ryoichi Nagatomi
}

Accepted: 7 December 2010/Published online: 25 December 2010

(C) The Author(s) 2010. This article is published with open access at Springerlink.com

\begin{abstract}
Aging is associated with decreased skeletal muscle function. Increased levels of advanced glycation end products (AGEs) in skeletal muscle tissue are observed with advancing age and in diabetes. Although serum AGE level is negatively associated with grip strength in elderly people, it is unknown whether this association is present in adult males. To determine the relationship between AGE accumulation in tissue and muscle strength and power among Japanese adult men. Skin autofluorescence (AF) (a noninvasive method for measuring tissue AGEs), grip strength $(n=232)$, and leg extension power $(n=138)$ were measured in Japanese adult men [median (interquartile range) age, $46.0(37.0,56.0)$ years]. After adjustment for potential confounders, the adjusted means [95\% confidence interval (CI)] for grip strength across the tertiles of skin $\mathrm{AF}$ were $44.5(43.2,45.9) \mathrm{kg}$ for the lowest tertile, $42.0(40.6,43.3) \mathrm{kg}$ for the middle tertile, and 41.7 (40.3, 43.1) $\mathrm{kg}$ for the highest tertile $(P$ for trend $<0.01$ ). Moreover, the adjusted geometric means $(95 \% \mathrm{CI})$ of leg
\end{abstract}

Communicated by Arnold de Haan.

H. Momma · Y. Kobayashi - L. Guan · M. Sato · H. Guo ·

M. Chujo · A. Otomo $\cdot$ C. Yufei $\cdot$ H. Tadaura

Department of Medicine and Science in Sports and Exercise,

Tohoku University Graduate School of Medicine, Sendai, Japan

K. Niu $\cdot$ T. Saito $\cdot$ R. Nagatomi $(\bowtie)$

Division of Biomedical Engineering for Health and Welfare, Tohoku University Graduate School of Biomedical Engineering, 2-1 Seiryo-machi, Aoba-ku, Sendai 980-8575, Japan

e-mail: nagatomi@m.tains.tohoku.ac.jp

T. Mori - T. Miyata

United Centers for Advanced Research and Translational

Medicine, Tohoku University Graduate School of Medicine,

Sendai, Japan extension power across the tertiles of skin AF were 17.8 $(16.6,19.1) \mathrm{W} / \mathrm{kg}$ for the lowest tertile, $17.5(16.4,18.7)$ $\mathrm{W} / \mathrm{kg}$ for the middle tertile, and $16.0(14.9,17.1) \mathrm{W} / \mathrm{kg}$ for the highest tertile $(P$ for trend $=0.04$ ). Among Japanese adult men, participants with higher skin AF had lower muscle strength and power, indicating a relationship between AGE accumulation and muscle strength and power. A long-term prospective study is required to clarify the causality.

Keywords Advanced glycation end products - Leg extension power - Grip strength - Carbonyl stress . Oxidative stress

\section{Introduction}

Ageing involves systemic accumulation of advanced glycation end products (AGEs), a diverse class of compounds resulting from glycation process under the strong influence of oxidative or carbonyl stress (Schleicher et al. 1997). In diabetic patients, increased accumulation of AGEs is observed (Schleicher et al. 1997; Singh et al. 2001). A common consequence of AGE accumulation is covalent cross-linking of AGEs to proteins, which leads to increased stiffness of protein matrix, impeding function and increasing resistance to removal of cross-linked proteins by proteolysis in various tissues and organs leading to impaired organ functions (Singh et al. 2001). Diabetic patients with end-stage renal disease had twice the concentrations of AGE in tissues compared with diabetic patients without renal disease (Makita et al. 1991).

Accumulation of AGE in the skeletal muscle tissue in elderly persons is suggested as one of the causes of decreased muscle force production (Haus et al. 2007). 
Diabetic status accelerates AGE accumulation in skeletal muscle tissue in rats (Snow et al. 2006; Snow and Thompson 2009). In cross sectional studies, the levels of blood $N^{\varepsilon}$-carboxymethyl-lysine (CML), a major AGE in vivo, were negatively associated with muscle function in groups of elderly population (Dalal et al. 2009; Semba et al. 2010). Since AGE gradually accumulates along the course of aging even without diabetes, it is possible that the level of AGE accumulation may be inversely associated with muscle strength and power.

Using a simple autofluorescent measurement of AGE levels in the skin, we examined the association between AGE accumulation and muscle strength and power in a population of Japanese adult men.

\section{Methods}

Study participants

The study participants consisted of adult men, who had been enrolled in a prospective study of the risk factors for lifestyle-related illnesses or health status among adult employees in Japan. Participants received annual health examination including anthropometric measurements, hematological examinations and additional assessment including muscle strength and power measurement in year 2009. The details of this study have been described elsewhere (Guo et al. 2010).

The sample selection process is described in Fig. 1. In 2009, 1,263 participants were enrolled in the annual examinations for lifestyle-related illnesses and health status. Of those enrolled, 1,215 participants agreed to join the survey, providing their informed consent for data analysis (response rate, 96.2\%). Because the number of female subjects was relatively small $(n=282)$, females were excluded from the analyses. Those who underwent skin AF measurement were randomly selected $(n=518)$. 272 participants who had lower skin reflection $(<10 \%)$ were also excluded (details described in the skin autofluorescence section below). As a result of these exclusions, the numbers of subjects included in the analyses for the relationship between skin $\mathrm{AF}$ and grip strength (analysis I) and leg extension power (analysis II) were 232 and 138, respectively. The protocol of this study was approved by the Institutional Review Board of the Tohoku University Graduate School of Medicine.

Skin autofluorescence (AF)

Skin AGE accumulation was assessed based on skin AF using an autofluorescence reader (AGE Reader; Diagnoptics, Groningen, The Netherlands) as described previously

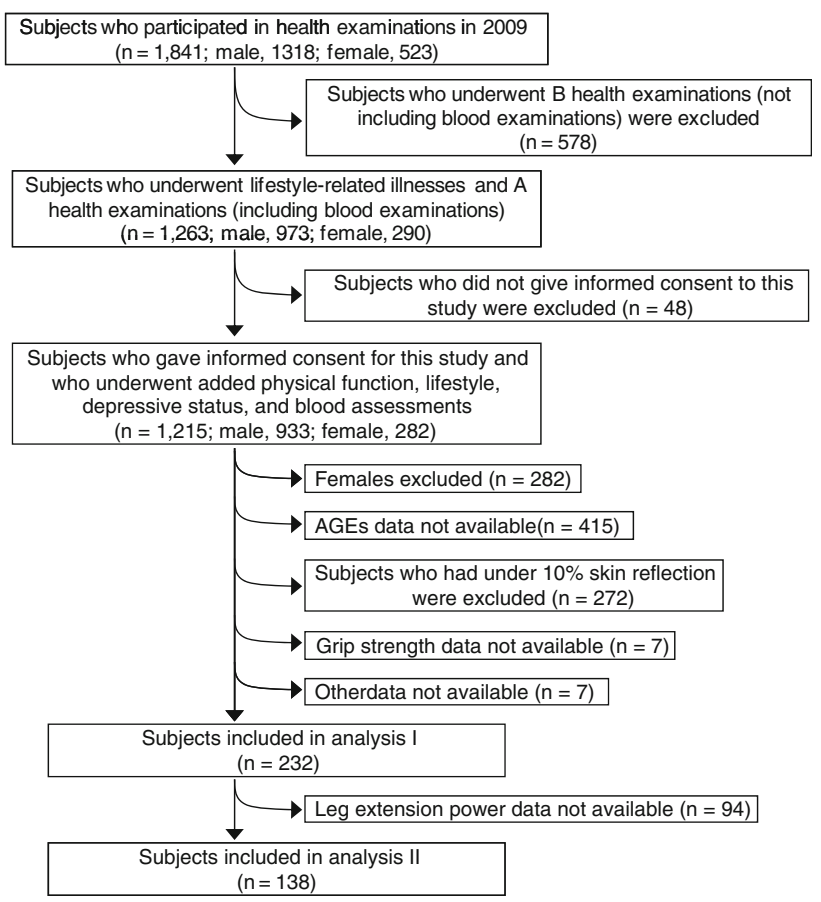

Fig. 1 Flow chart of the sample selection process

(Meerwaldt et al. 2004). The AGE Reader consists of a tabletop box equipped with an excitation light source. Each measurement took approximately $30 \mathrm{~s}$ to complete by an independent observer. Excitation light in the wavelength range of $300-420 \mathrm{~nm}$ is projected onto the skin surface through a $1-\mathrm{cm}^{2}$ hole. The intensity of light emitted from the skin at wavelengths between 420 and $600 \mathrm{~nm}$ is measured with a spectrometer via a glass fiber. Skin AF is calculated by dividing the mean value of the emitted light intensity per $\mathrm{nm}$ between 420 and $600 \mathrm{~nm}$ by the mean value of the excitation light intensity per nm between 300 and $420 \mathrm{~nm}$; the result is expressed in arbitrary units (AU) and multiplied by 100 for easier evaluation. Skin AF has been validated to correspond to specific AGEs measured in human skin biopsy samples in several patient groups and healthy controls (Meerwaldt et al. 2004, 2005). The intra-assay coefficient of variation for repeated $\mathrm{AF}$ reader measurement on the same day was 5.0\% (Meerwaldt et al. 2004).

All autofluorescence measurements were performed at room temperature on the volar side of the lower right arm, approximately $10-15 \mathrm{~cm}$ below the elbow fold, with the participants in a seated position. Care was taken to perform the measurement at a normal skin site, without visible vessels, scars, lichenification, or other skin abnormalities. The arm of each subject was covered with a black cloth in order to avoid any influence of external light during the measurement. Since skin pigmentation influences autofluorescence measurement, in particular when skin reflection is below $10 \%$, autofluorescence values were not used 
in this study when skin reflection was below $10 \%$ (Na et al. 2001).

\section{Muscle strength and power}

Grip strength and leg extension power were measured. Grip strength was measured with a digital Smedley-type hand dynamometer (T.K.K.5401; Takei Scientific Instruments Co., Ltd, Niigata, Japan). The participants were told to adjust the device for hand comfort and fit and to place their arm in a relaxed, stationary position. Highest grip strength force of either right or left arm was used as representative grip strength.

Leg extension power was measured by Aneropress 3500 (Combi Wellness, Tokyo, Japan). Each participant was placed well back on a seat, the waist was fixed with a belt, and the knee joint angled at $90^{\circ}$. Isometric contractions lasted for $5 \mathrm{~s}$ each and were separated by 15 -s rest intervals. Peak power was detected, calculated, and recorded in watts with a microcomputer. The highest measurement among five trials was recorded as "isometric strength performance." To reduce the bias related to differences in body mass, leg extension power was expressed as the peak of the leg power relative to body weight $(\mathrm{W} / \mathrm{kg})$.

\section{Assessment of other variables}

Depressive symptoms were assessed according to the Japanese version (Fukuda and Kobayashi 1973) of the SelfRating Depression Scale (SDS). Participants were considered as depressive when SDS score was 45 or more (Fountoulakis et al. 2001). Blood pressure (BP) in the left upper arm was measured twice using an automatic device (YAMASU605P; Kenzmedico Co. Ltd., Saitama, Japan) following a 5-min rest in the sitting position. The mean values were used as the BP value.

Blood samples were drawn from the antecubital vein, with minimal tourniquet use, while the subjects were seated. Specimens were collected in siliconized vacuum glass tubes containing sodium fluoride for fasting blood glucose and no additives for lipid analyses. Fasting blood glucose concentration was measured by enzymatic methods (Eerotec, Tokyo, Japan). The triglyceride (TG), lowdensity lipoprotein cholesterol (LDL-C), and high-density lipoprotein cholesterol (HDL-C) concentrations were measured by enzymatic methods using appropriate kits (Sekisui Medical, Tokyo, Japan).

Information on age, smoking status (never, former, or currently smoking), alcohol-drinking status (never, $\geq 1$ day/week, or 7 days/week), occupation (desk work or non-desk work), history of physical illness and current medication use ("yes" or "no") of the participants were obtained from a questionnaire. The educational level was assessed by determining the last grade level and divided into two categories: less than college level or college-level and above. Levels of daily physical activity (PA) were estimated using the International Physical Activity Questionnaire (Japanese version) (Craig et al. 2003). PA was categorized into tertiles with similar numbers of individuals in each group (low, middle, or high). Total energy consumption and vitamin $\mathrm{C}$ intake were estimated using a brief self-administered diet history questionnaire (Sasaki 2005). A diagnosis of metabolic syndrome (MS) was defined according to the modified Japanese criteria [defined by the Japanese Society for the Study of Obesity (JASSO)] (Matsuzawa 2005).

\section{Statistical analysis}

All statistical analyses were performed using the SPSS 17.0 statistical software package for Windows (SPSS, Inc., Chicago, IL, USA).

In this study, because the distribution of all continuous variables, except for grip strength and systolic blood pressure, was not normal, the common logarithm was applied to normalize the data before statistical analysis. The Spearman rank correlation test was performed. ANCOVA was used to examine the relationships between skin AF and grip strength (analysis I, $n=232$ ) or logtransformed leg extension power (analysis II, $n=138$ ), adjusting for age and body mass index (model 1); all of the above parameters, in addition to PA, smoking status, drinking status, depressive symptoms, educational level, occupation, and total energy consumption, were used in model 2; all parameters in model 2 plus MS, diabetes, and kidney disease were used in model 3 ; and all parameters in model 3 plus vitamin C intake were used in model 4 (Fig. 1). ANCOVA was performed with the forced entry of all factors considered to be potential covariates. Bonferroni-corrected $P$ values were used for comparisons between groups differing in skin AF. All $P$ values for linear trends were calculated; all tests for statistical significance were two sided, and $P<0.05$ was defined as statistically significant.

\section{Results}

The number of participants with skin reflection above $10 \%$ was $246(47.5 \%)$, and the median (interquartile range) skin AF was $1.98(1.78,2.18)$ AU. The participant characteristics according to the tertiles of skin AF in analysis I are presented in Table 1. Subjects in the highest tertile of skin AF tended to be older and had a higher fasting glucose concentration ( $P$ for trend $<0.01$ and 0.06 , respectively); this group also had a higher percentage of current smokers compared with that in the lowest tertile $(P$ for trend $<0.01)$. Otherwise, no 
Table 1 Characteristics of the participants according to the tertiles of skin autofluorescence in analysis I $(n=232)$

\begin{tabular}{|c|c|c|c|c|}
\hline \multirow[t]{2}{*}{ Range (unit, AU) } & \multicolumn{3}{|c|}{ Tertiles of skin autofluorescence } & \multirow[t]{2}{*}{$P$ for trend } \\
\hline & $\begin{array}{l}\text { Low }(n=78) \\
(1.28-1.84)\end{array}$ & $\begin{array}{l}\text { Middle }(n=77) \\
(1.84-2.09)\end{array}$ & $\begin{array}{l}\text { High }(n=77) \\
(2.09-4.44)\end{array}$ & \\
\hline Age (years) & $40.0(35.0,51.0)$ & $45.0(38.0,57.0)$ & $52.0(40.0,58.5)$ & $<0.01$ \\
\hline BMI $(\mathrm{kg} / \mathrm{m})$ & $23.7(22.1,25.7)$ & $23.7(21.8,25.9)$ & $23.6(21.7,26.2)$ & 0.89 \\
\hline Waist circumference $(\mathrm{cm})$ & $84.0(77.8,91.0)$ & $86.0(79.5,90.5)$ & $85.0(80.0,91.5)$ & 0.29 \\
\hline $\mathrm{SBP}(\mathrm{mmHg})$ & $130.0(120.0,137.3)$ & $129.0(116.0,139.0)$ & $130.0(120.0,142.0)$ & 0.42 \\
\hline DBP (mmHg) & $80.0(74.0,90.0)$ & $80.0(76.0,88.5)$ & $84.0(74.0,90.0)$ & 0.44 \\
\hline Fasting blood glucose (mg/dl) & $92.0(88.8,97.5)$ & $93.0(88.0,100.0)$ & $95.0(88.5,103.5)$ & 0.06 \\
\hline TG (mg/dl) & $110.5(69.5,153.5)$ & $141.0(79.5,198.5)$ & $131.0(86.0,186.5)$ & 0.09 \\
\hline LDL (mg/dl) & $120.0(93.0,139.0)$ & $121.0(95.0,133.0)$ & $122.0(109.0,144.5)$ & 0.21 \\
\hline HDL (mg/dl) & $53.0(45.5,63.3)$ & $50.0(42.5,59.0)$ & $52.0(42.5,56.5)$ & 0.15 \\
\hline Total energy intake (kcal/d) & $1910.9(1599.7,2409.1)$ & $1806.8(1569.9,2201.5)$ & $1747.7(1416.0,2267.8)$ & 0.39 \\
\hline Vitamin C intake $([\mathrm{mg} / \mathrm{d}] / 2000 \mathrm{kcal})$ & $84.0(61.4,121.9)$ & $93.8(73.1,128.6)$ & $95.9(66.7,126.4)$ & 0.72 \\
\hline High PA (\%, median values: 48.0 METs·h/week) & 43.6 & 28.6 & 40.3 & 0.09 \\
\hline $\begin{array}{l}\text { Middle PA (\%, median values: } \\
\text { 12.1 METs.h/week) }\end{array}$ & 39.7 & 46.8 & 36.4 & 0.05 \\
\hline \multicolumn{5}{|l|}{ Smoking status } \\
\hline Current $(\%)$ & 29.5 & 40.3 & 49.4 & 0.04 \\
\hline Former $(\%)$ & 12.8 & 20.8 & 10.4 & 0.17 \\
\hline \multicolumn{5}{|l|}{ Drinking status } \\
\hline 7 drinks/week (\%) & 28.2 & 29.9 & 23.4 & 0.64 \\
\hline$\geq 1$ drinks/week $(\%)$ & 59.0 & 54.5 & 58.4 & 0.83 \\
\hline Depressive symptoms (SDS $\geq 45, \%$ ) & 30.8 & 31.2 & 29.9 & 0.98 \\
\hline Education ( $\geq$ college, \%) & 43.6 & 35.1 & 40.3 & 0.55 \\
\hline Desk work (\%) & 87.2 & 74.0 & 77.9 & 0.12 \\
\hline Diabetes (\%) & 6.4 & 10.4 & 9.1 & 0.67 \\
\hline Kidney disease (\%) & 2.6 & 1.3 & 6.5 & 0.23 \\
\hline MS (JASSO, \%) & 20.5 & 24.7 & 27.3 & 0.61 \\
\hline
\end{tabular}

Data are medians (interquartile range) or proportions

$A U$ arbitrary units, $B M I$ body mass index, $S B P$ systolic blood pressure, $D B P$ diastolic blood pressure, $T G$ triglyceride, $L D L$ low-density lipoprotein cholesterol, $H D L$ high-density lipoprotein-cholesterol, $P A$ physical activity, $S D S$ self-rating depression scale, $M S$ metabolic syndrome, JASSO Japanese Society for the Study of Obesity

${ }^{a}$ Analysis of variance or logistic regression

significant differences were observed among the tertiles of skin AF. In Fig. 2a, outlier (skin $\mathrm{AF}=4.44$ A.U.) was a person with both diabetes and kidney disease, and skin $\mathrm{AF}$ correlated with age $(r=0.31, P<0.01)$.

Table 2 shows the relationship of skin AF tertiles to grip strength. In the final multivariate models, the adjusted means [95\% confidence interval (CI)] of the grip strength across the tertiles of skin AF was $44.5(43.2,45.9) \mathrm{kg}$ for the lowest tertile, $42.0(40.6,43.3) \mathrm{kg}$ for the middle tertile, and $41.7(40.3,43.1) \mathrm{kg}$ for the highest tertile $(P$ for trend $<0.01)$. The adjusted mean grip strength was $6.3 \%$ lower for the highest tertile of skin AF than for the lowest tertile of skin AF (Bonferroni-corrected $P$ value $=0.01$ ).

To assess the relationship between skin AF tertiles and leg extension power, we performed an additional analysis (analysis II) that excluded those subjects who did not undergo the leg extension power test $(n=138)$. Table 3 shows the participant characteristics according to tertiles of skin AF in analysis II. In analysis II, subjects in the highest tertile of skin $\mathrm{AF}$ were older and had higher fasting glucose concentrations compared with those in the lowest tertile ( $P$ for trend $<0.01$ and 0.02 , respectively). Although no significant difference was observed in the percentage of current smokers, the prevalence of diabetes in the highest tertile of skin AF tended to be higher than that of the lowest tertile ( $P$ for trend $=0.05$ ). In the Spearman rank correlation test, skin AF correlated with age $(r=0.34$, $P<0.01$ ) (Fig. 2b).

Table 4 shows the relationship of the tertiles of skin AF with leg extension power. In the final multivariate models, the adjusted geometric mean $(95 \% \mathrm{CI})$ of log-transformed leg extension power across the tertiles of skin $\mathrm{AF}$ was 17.8 

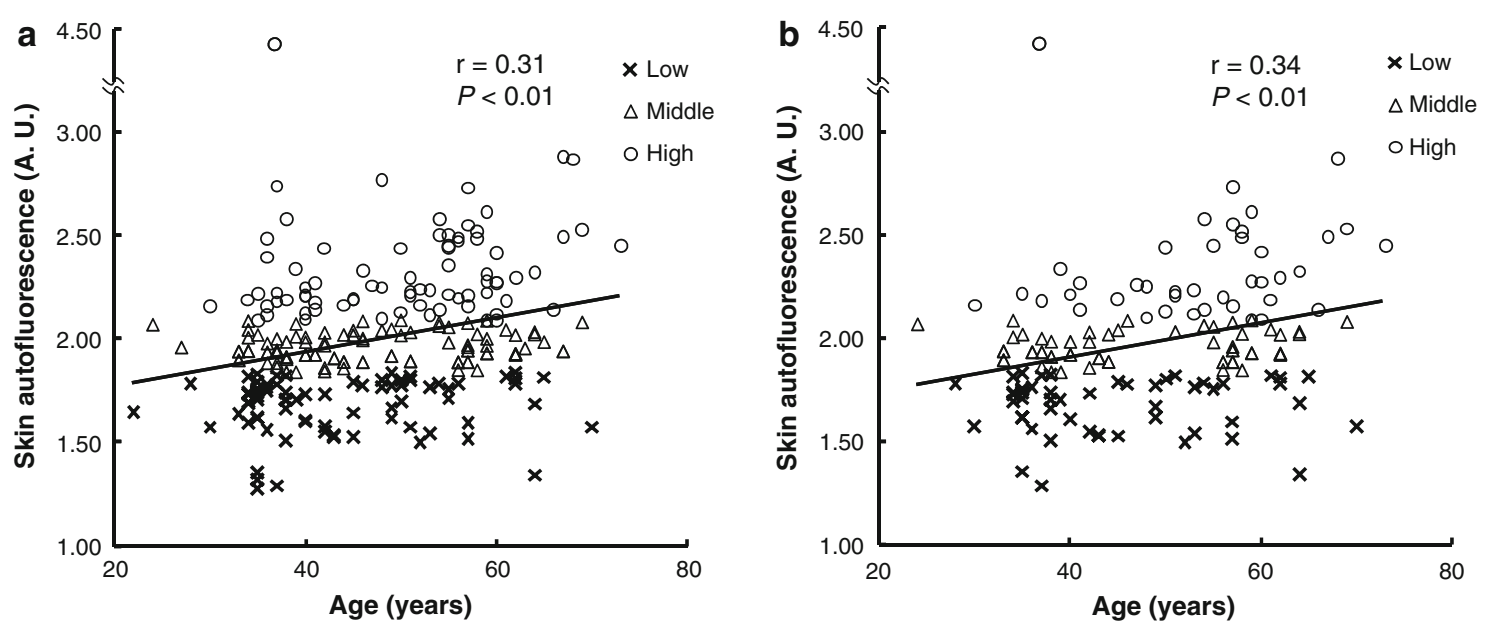

Fig. 2 Correlation between skin autofluorescence and age in analysis I (a) and analysis II (b). Spearman rank correlation test was performed. Cross, triangle, and circle symbols are represented as the lower, middle, and higher tertile of skin autofluorescence, respectively

Table 2 Relationship of the tertile of skin autofluorescence with grip strength $(n=232)$

\begin{tabular}{|c|c|c|c|c|}
\hline \multirow[t]{2}{*}{ Range (unit, AU) } & \multicolumn{3}{|c|}{ Tertiles of skin autofluorescence } & \multirow[t]{2}{*}{$P$ for trend } \\
\hline & $\begin{array}{l}\text { Low } \\
(1.28-1.84)\end{array}$ & $\begin{array}{l}\text { Middle } \\
(1.84-2.09)\end{array}$ & $\begin{array}{l}\text { High } \\
(2.09-4.44)\end{array}$ & \\
\hline No. of participants & 78 & 77 & 77 & - \\
\hline \multicolumn{5}{|l|}{ Grip strength (kg) } \\
\hline Crude & $44.7(43.3,46.1)$ & $41.7(40.3,43.1)^{\mathrm{f}}$ & $41.8(40.4,43.2)^{\mathrm{f}}$ & $<0.01$ \\
\hline Model $1^{\mathrm{b}}$ & $44.3(43.0,45.7)$ & $41.8(40.4,43.1)^{\mathrm{f}}$ & $42.1(40.8,43.5)$ & 0.03 \\
\hline Model $2^{\mathrm{c}}$ & $44.5(43.2,45.9)$ & $42.0(40.7,43.4)^{\mathrm{f}}$ & $41.6(40.2,43.0)^{\mathrm{f}}$ & $<0.01$ \\
\hline Model $3^{\mathrm{d}}$ & $44.5(43.2,45.9)$ & $42.0(40.7,43.3)^{\mathrm{f}}$ & $41.7(40.3,43.0)^{\mathrm{f}}$ & $<0.01$ \\
\hline Model $4^{\mathrm{e}}$ & $44.5(43.2,45.9)$ & $42.0(40.6,43.3)^{\mathrm{f}}$ & $41.7(40.3,43.1)^{\mathrm{f}}$ & $<0.01$ \\
\hline
\end{tabular}

Data are means (95\% confidence interval). Unit of grip strength is $\mathrm{kg}$

$A U$ arbitrary units

${ }^{a}$ Analysis of variance or analysis of covariance

b Adjusted for age (continuous variables, log-transformed), body mass index (continuous variables, log-transformed)

c Additionally adjusted for physical activity (tertiles), smoking status (never, former, or current), drinking status (never, $\geq 1$ drinks/week, or 7 drinks/week), depressive symptoms (self-rating depression scale $\geq 45$ ), educational level ( $\geq$ college), occupation (desk work or non-desk work), and total energy consumption (continuous variables, log-transformed)

d Additionally adjusted for metabolic syndrome (Japanese Society for the Study of Obesity) (no or yes), diabetes (no or yes), and kidney disease (no or yes)

e Additionally adjusted for dietary intake of vitamin C (continuous variables, log-transformed)

${ }^{\mathrm{f}}$ Significantly different from lowest skin autofluorescence tertile (Bonferroni correction), $P<0.05$

$(16.6,19.1) \mathrm{W} / \mathrm{kg}$ for the lowest tertile, $17.5(16.4,18.7)$ $\mathrm{W} / \mathrm{kg}$ for the middle tertile, and $16.0(14.9,17.1) \mathrm{W} / \mathrm{kg}$ for the highest tertile $(P$ for trend $=0.04)$.

\section{Discussion}

The present study examined the relationship between skin AF representing AGE accumulation and muscle strength and power and power among Japanese adult men. Consistent with previous studies (Dalal et al. 2009; Semba et al. 2010), our results showed that the level of skin AF was independently associated with muscle strength and power. These results suggest that greater AGE accumulation is associated with reduced muscle strength and power not only in older people but also in younger adults, and that AGE accumulation may be a predisposing factor for muscle force reduction along the course of aging finally leading to sarcopenia.

There is an increasing evidence supporting the hypothesis that AGEs may play a role in the decline of muscle 
Table 3 Characteristics of the participants according to the tertiles of skin autofluorescence in analysis II $(n=138)$

\begin{tabular}{|c|c|c|c|c|}
\hline \multirow[t]{2}{*}{ Range (unit, AU) } & \multicolumn{3}{|c|}{ Tertiles of skin autofluorescence } & \multirow[t]{2}{*}{$P$ for trend ${ }^{\mathrm{a}}$} \\
\hline & $\begin{array}{l}\text { Low }(n=46) \\
(1.28-1.84)\end{array}$ & $\begin{array}{l}\text { Middle }(n=46) \\
(1.84-2.09)\end{array}$ & $\begin{array}{l}\text { High }(n=46) \\
(2.09-4.44)\end{array}$ & \\
\hline Age (years) & $42.5(35.0,53.3)$ & $43.5(37.0,57.0)$ & $55.5(46.8,60.0)$ & $<0.01$ \\
\hline BMI $(\mathrm{kg} / \mathrm{m})$ & $23.7(21.7,25.6)$ & $23.8(21.9,25.8)$ & $23.4(21.5,25.9)$ & 0.92 \\
\hline Waist circumference $(\mathrm{cm})$ & $84.0(77.0,92.0)$ & $87.0(78.8,92.0)$ & $86.0(80.8,91.3)$ & 0.38 \\
\hline SBP (mmHg) & $128.0(119.5,137.8)$ & $130.0(115.5,140.3)$ & $132.0(117.5,140.0)$ & 0.59 \\
\hline DBP (mmHg) & $80.0(73.5,88.3)$ & $80.0(73.5,90.3)$ & $81.5(75.5,86.3)$ & 0.61 \\
\hline Fasting blood glucose (mg/dl) & $93.0(88.8,100.3)$ & $90.5(88.0,96.0)$ & $96.0(88.5,105.3)$ & 0.02 \\
\hline TG (mg/dl) & $111.5(69.5,154.3)$ & $140.0(75.8,187.8)$ & $131.5(84.0,186.0)$ & 0.41 \\
\hline LDL (mg/dl) & $117.5(91.0,137.5)$ & $123.0(105.3,133.0)$ & $121.0(109.0,152.8)$ & 0.27 \\
\hline HDL (mg/dl) & $53.0(45.5,61.8)$ & $52.0(43.8,59.0)$ & $53.5(44.0,60.0)$ & 0.73 \\
\hline Total energy intake (kcal/d) & $1887.1(1509.9,2378.0)$ & $1783.3(1580.2,2244.2)$ & $1655.2(1354.0,2314.1)$ & 0.47 \\
\hline Vitamin C intake $([\mathrm{mg} / \mathrm{d}] / 2000 \mathrm{kcal})$ & $82.4(61.4,127.7)$ & $97.1(65.9,124.5)$ & $103.7(76.2,132.5)$ & 0.36 \\
\hline High PA ( $\%$, median values: 48.0 METs·h/week) & 39.1 & 28.3 & 32.6 & 0.54 \\
\hline Middle PA (\%, median values: 12.1 METs·h/week) & 32.6 & 34.8 & 32.6 & 0.97 \\
\hline \multicolumn{5}{|l|}{ Smoking status } \\
\hline Current $(\%)$ & 28.3 & 34.8 & 41.3 & 0.43 \\
\hline Former $(\%)$ & 10.9 & 19.6 & 15.2 & 0.52 \\
\hline \multicolumn{5}{|l|}{ Drinking status } \\
\hline 7 drinks/week $(\%)$ & 28.3 & 34.8 & 17.4 & 0.17 \\
\hline$\geq 1$ drinks/week $(\%)$ & 60.9 & 52.2 & 56.5 & 0.73 \\
\hline Depressive symptoms (SDS $\geq 45, \%$ ) & 28.3 & 34.8 & 32.6 & 0.56 \\
\hline Education ( $\geq$ college, \%) & 39.1 & 37.0 & 39.1 & 0.97 \\
\hline Desk work (\%) & 89.1 & 69.6 & 84.8 & 0.05 \\
\hline Diabetes $(\%)$ & 6.5 & 6.5 & 19.6 & 0.09 \\
\hline Kidney disease (\%) & 2.2 & 2.2 & 2.2 & 1.00 \\
\hline MS (JASSO, \%) & 19.6 & 26.1 & 21.7 & 0.75 \\
\hline
\end{tabular}

Data are medians (interquartile range) or proportions

$A U$ arbitrary units, $B M I$ body mass index, $S B P$ systolic blood pressure, $D B P$ diastolic blood pressure, $T G$ triglyceride, $L D L$ low-density lipoprotein cholesterol, $H D L$ high-density lipoprotein-cholesterol, $P A$ physical activity, $S D S$ self-rating depression scale, $M S$ metabolic syndrome, JASSO Japanese Society for the Study of Obesity

${ }^{a}$ Analysis of variance or logistic regression

function, which may eventually lead to sarcopenia in the older age. First, AGE accumulation in skeletal muscle is greater in fast muscle fiber types, which are well known to possess a faster shortening velocity and larger force production (Snow and Thompson 2009). Second, AGEmodified proteins in skeletal muscle include several critical enzymes involved in energy production, such as creatine kinase (Snow et al. 2007). Third, glycation of skeletal muscle myosin changed the structural property of the protein and reduced simultaneously the in vitro motility speed (Ramamurthy et al. 2001). Moreover, because the binding of AGEs to RAGE results in depletion of cellular antioxidant defense mechanisms and the generation of oxygen-free radicals (Schmidt et al. 1994), oxidant damage to myofibrillar proteins may play a role in the age-related reduction of contractile capacity (Thompson 2009). AGE-RAGE interaction also induces microcirculatory dysfunction by endothelial dysfunction or inflammation (Brownlee 2001; Payne 2006). Thus, AGE accumulation may contribute to decreased muscle function with aging through a variety of mechanisms.

It is well known that vitamin $\mathrm{C}$ is one of the primary antioxidants. Because greater intake of vitamin $\mathrm{C}$ was independently associated with muscle strength (Cesari et al. 2004), dietary intake of vitamin $C$ may potentially influence the relationship between skin $\mathrm{AF}$ and muscle strength and power. In this study, because the relationship between higher skin AF and lower muscle strength and power remained even after adjusting the intake of vitamin $\mathrm{C}$, higher skin AF could be associated with lower muscle strength and power independent of dietary intake of vitamin $C$ in healthy adult men. 
Table 4 Relationship of the tertile of skin autofluorescence with log-transformed leg extension power $(n=138)$

\begin{tabular}{|c|c|c|c|c|}
\hline \multirow[t]{2}{*}{ Range (unit, AU) } & \multicolumn{3}{|c|}{ Tertiles of skin autofluorescence } & \multirow[t]{2}{*}{$P$ for trend } \\
\hline & $\begin{array}{l}\text { Low } \\
(1.29-1.81)\end{array}$ & $\begin{array}{l}\text { Middle } \\
(1.81-2.07)\end{array}$ & $\begin{array}{l}\text { High } \\
(2.07-4.44)\end{array}$ & \\
\hline No. of participants & 46 & 46 & 46 & - \\
\hline \multicolumn{5}{|c|}{ Leg extension power (W/kg) } \\
\hline Crude & $18.6(17.0,20.0)$ & $17.4(16.2,19.1)$ & $15.5(14.5,16.2)^{\mathrm{f}}$ & $<0.01$ \\
\hline Model $1^{\mathrm{b}}$ & $18.2(17.0,19.5)$ & $17.4(16.2,18.6)$ & $15.8(14.8,17.0)^{\mathrm{f}}$ & 0.01 \\
\hline Model $2^{\mathrm{c}}$ & $17.8(16.6,19.1)$ & $17.4(16.2,18.6)$ & $15.8(14.8,17.4)$ & $<0.05$ \\
\hline Model $3^{\mathrm{d}}$ & $17.8(16.6,19.1)$ & $17.4(16.2,18.6)$ & $16.2(14.8,17.4)$ & 0.05 \\
\hline Model $4^{\mathrm{e}}$ & $17.8(16.6,19.1)$ & $17.5(16.4,18.7)$ & $16.0(14.9,17.1)$ & 0.04 \\
\hline
\end{tabular}

Data are geometric means (95\% confidence interval). Unit of leg extension power is $\mathrm{W} / \mathrm{kg}$

$A U$ arbitrary units

${ }^{\text {a }}$ Analysis of variance or analysis of covariance

b Ajusted for age (continuous variables, log-transformed), body mass index (continuous variables, log-transformed)

c Additionally adjusted for physical activity (tertiles), smoking status (never, former, or current), drinking status (never, $\geq 1$ drinks/week, or 7 drinks/week), depressive symptoms (self-rating depression scale $\geq 45$ ), educational level ( $\geq$ college), occupation (desk work, or non-desk work), and total energy consumption (continuous variables, log-transformed)

d Additionally adjusted for metabolic syndrome (Japanese Society for the Study of Obesity) (no or yes), diabetes (no or yes), and kidney disease (no or yes)

e Additionally adjusted for dietary intake of vitamin C (continuous variables, log-transformed)

${ }^{\mathrm{f}}$ Significantly different from lowest skin autofluorescence tertile (Bonferroni correction), $P<0.05$

In this study, skin $\mathrm{AF}$ was used as a measure for skin AGE accumulation. Previous studies reported that skin AF is correlated with blood AGEs (Tanaka et al. 2009), or not (Hartog et al. 2008). In this study, our findings conform to previous studies which measured circulating CML (Dalal et al. 2009; Semba et al. 2010). Thus, it is speculated that skin $\mathrm{AF}$ is potentially correlated with blood AGEs in our participants.

This study has other limitations. First, this study focused only on men. Whether the relationship is present in younger women is unknown. Moreover, although we adjusted for confounders such as lifestyle factors or disease, we cannot exclude the possibility that muscle strength and power was affected by other factors associated with lifestyle, disease, or protein damage in skeletal tissue that correlate with AGE accumulation. Finally, because this study was a crosssectional study, we could not conclude whether AGE accumulation in tissue decreased muscle strength and power. A prospective study or trial should be undertaken to further confirm the causal relationship between AGE accumulation and muscle strength and power.

\section{Conclusion}

The participants-apparently healthy adult men-with higher skin AF associated with AGE accumulation had lower muscle strength and power. Further studies are needed to confirm whether increased AGE accumulation in tissue predict a decline in muscle strength and power with advancing age in younger adults.

Acknowledgments We gratefully acknowledge all the subjects for participating in our study and the Sendai Oroshisho Center for allowing us to perform the study. This work was supported by a Grantin-Aid under the "Knowledge Cluster Initiative" from the Ministry of Education, Culture, Sports, Science and Technology of Japan. The present study complies with the current laws of Japan and the protocol of the present study was approved by the Institutional Review Board of the Tohoku University Graduate School of Medicine.

Conflict of interest None of the authors have any conflicts of interest to disclose.

Open Access This article is distributed under the terms of the Creative Commons Attribution Noncommercial License which permits any noncommercial use, distribution, and reproduction in any medium, provided the original author(s) and source are credited.

\section{References}

Brownlee M (2001) Biochemistry and molecular cell biology of diabetic complications. Nature 414:813-820

Cesari M, Pahor M, Bartali B, Cherubini A, Penninx BW, Williams GR, Atkinson H, Martin A, Guralnik JM, Ferrucci L (2004) Antioxidants and physical performance in elderly persons: the Invecchiare in Chianti (InCHIANTI) study. Am J Clin Nutr 79:289-294

Craig CL, Marshall AL, Sjostrom M, Bauman AE, Booth ML, Ainsworth BE, Pratt M, Ekelund U, Yngve A, Sallis JF, Oja P (2003) International physical activity questionnaire: 12-country reliability and validity. Med Sci Sports Exerc 35:1381-1395 
Dalal M, Ferrucci L, Sun K, Beck J, Fried LP, Semba RD (2009) Elevated serum advanced glycation end products and poor grip strength in older community-dwelling women. J Gerontol A Biol Sci Med Sci 64:132-137

Fountoulakis KN, lacovides A, Samolis S, Kleanthous S, Kaprinis SG, St. Kaprinis G, Bech P (2001) Reliability, validity and psychometric properties of the Greek translation of the Zung Depression Rating Scale. BMC Psychiatry 1:6

Fukuda K, Kobayashi S (1973) A study on a self-rating depression scale (author's transl). Seishin Shinkeigaku Zasshi 75:673-679 (in Japanese)

Guo H, Niu K, Monma H, Kobayashi Y, Guan L, Sato M, Minamishima D, Nagatomi R (2010) Association of Japanese dietary pattern with serum adiponectin concentration in Japanese adult men. Nutr Metab Cardiovasc Dis. doi:101016/ jnumecd201006006

Hartog JW, Hummel YM, Voors AA, Schalkwijk CG, Miyata T, Huisman RM, Smit AJ, Van Veldhuisen DJ (2008) Skinautofluorescence, a measure of tissue advanced glycation endproducts (AGEs), is related to diastolic function in dialysis patients. J Card Fail 14:596-602

Haus JM, Carrithers JA, Trappe SW, Trappe TA (2007) Collagen, cross-linking, and advanced glycation end products in aging human skeletal muscle. J Appl Physiol 103:2068-2076

Makita Z, Radoff S, Rayfield EJ, Yang Z, Skolnik E, Delaney V, Friedman EA, Cerami A, Vlassara H (1991) Advanced glycosylation end products in patients with diabetic nephropathy. N Engl J Med 325:836-842

Matsuzawa Y (2005) Metabolic syndrome-definition and diagnostic criteria in Japan. J Atheroscler Thromb 12:301

Meerwaldt R, Graaff R, Oomen PH, Links TP, Jager JJ, Alderson NL, Thorpe SR, Baynes JW, Gans RO, Smit AJ (2004) Simple noninvasive assessment of advanced glycation endproduct accumulation. Diabetologia 47:1324-1330

Meerwaldt R, Hartog JW, Graaff R, Huisman RJ, Links TP, den Hollander NC, Thorpe SR, Baynes JW, Navis G, Gans RO, Smit AJ (2005) Skin autofluorescence, a measure of cumulative metabolic stress and advanced glycation end products, predicts mortality in hemodialysis patients. J Am Soc Nephrol 16:3687-3693

Na R, Stender IM, Henriksen M, Wulf HC (2001) Autofluorescence of human skin is age-related after correction for skin pigmentation and redness. J Invest Dermatol 116:536-540
Payne GW (2006) Effect of inflammation on the aging microcirculation: impact on skeletal muscle blood flow control. Microcirculation 13:343-352

Ramamurthy B, Hook P, Jones AD, Larsson L (2001) Changes in myosin structure and function in response to glycation. FASEB J $15: 2415-2422$

Sasaki S (2005) Serum biomarker-based validation of a brief-type self-administered diet history questionnaire for Japanese subjects. The Study Group of Ministry of Health, Labor and Welfare of Japan, Tanaka H, chairman, "A research for assessment of nutrition and dietary habit in "Kenko Nippon 21", 10-42 (in Japanese)

Schleicher ED, Wagner E, Nerlich AG (1997) Increased accumulation of the glycoxidation product $N$ (epsilon)-(carboxymethyl)lysine in human tissues in diabetes and aging. J Clin Invest 99:457-468

Schmidt AM, Hori O, Brett J, Yan SD, Wautier JL, Stern D (1994) Cellular receptors for advanced glycation end products. Implications for induction of oxidant stress and cellular dysfunction in the pathogenesis of vascular lesions. Arterioscler Thromb 14:1521-1528

Semba RD, Bandinelli S, Sun K, Guralnik JM, Ferrucci L (2010) Relationship of an advanced glycation end product, plasma carboxymethyl-lysine, with slow walking speed in older adults: the InCHIANTI study. Eur J Appl Physiol 108:191-195

Singh R, Barden A, Mori T, Beilin L (2001) Advanced glycation endproducts: a review. Diabetologia 44:129-146

Snow LM, Thompson LV (2009) Influence of insulin and muscle fiber type in nepsilon-(carboxymethyl)-lysine accumulation in soleus muscle of rats with streptozotocin-induced diabetes mellitus. Pathobiology 76:227-234

Snow LM, Lynner CB, Nielsen EM, Neu HS, Thompson LV (2006) Advanced glycation end product in diabetic rat skeletal muscle in vivo. Pathobiology 73:244-251

Snow LM, Fugere NA, Thompson LV (2007) Advanced glycation end-product accumulation and associated protein modification in type II skeletal muscle with aging. J Gerontol A Biol Sci Med Sci 62:1204-1210

Tanaka T, Katoh T, Asai J, Nemoto F, Suzuki H, Asahi K, Sato K, Sakaue M, Miyata T, Watanabe T (2009) Relationship of skin autofluorescence to cardiovascular disease in japanese hemodialysis patients. Ther Apher Dial 14:334-340

Thompson LV (2009) Age-related muscle dysfunction. Exp Gerontol 44:106-111 